\title{
HIV-RELATED KNOWLEDGE, ATTITUDES AND SEXUAL RISK BEHAVIOURS AMONG MONTENEGRIN YOUTH
}

\author{
Itana Labović1 ${ }^{\text {, Nataša Terzić }}$, Rajko Strahinja ${ }^{3}$, Boban Mugoša ${ }^{2}$, Dragan Laušević ${ }^{2}$, Zoran Vratnica ${ }^{2}$ \\ ${ }^{1}$ Institute of Public Health/United Nations Development Programme -Country Office Montenegro \\ ${ }^{2}$ Institute of Public Health \\ ${ }^{3}$ Ministry of Health of Montenegro
}

\section{ABSTRACT}

Context: Montenegro has a low-level HIV epidemic, but the majority of registered HIV cases have been diagnosed in patients between the ages of 20- to 34-years-old. The aim of this study was to assess the level of HIV-related knowledge, attitudes towards people living with HIV (PLHIV) and sexual behaviour among youth aged 15-24 in Montenegro.

Methods: A nationally representative cross-sectional survey assessed 1164 young people aged 15-24. The data were collected in December 2009 using face-to-face interviewing for topics concerning HIV-related awareness and attitudes, whereas a self-administered questionnaire covered topics related to sexual experiences and behaviour.

Results: In general, the level of HIV-related knowledge and accepting attitudes towards people living with HIV were unsatisfactory. Of the surveyed population, slightly more

\section{INTRODUCTION}

Montenegro has a low-level HIV epidemic and an overall HIV prevalence of $0.01 \%$. The HIV infection rate appears to be stable, with 7-12 new cases diagnosed each year. Since 1989 when the index case was detected, there have been 115 registered HIV/AIDS cases and 35 AIDSrelated deaths. The most important transmission routes in Montenegro seem to be heterosexual (48\%) and homo/ bisexual intercourse (36\%). Recently, there has been a notable shift from heterosexual to homosexual transmission routes among newly registered cases. More than 60\% of registered HIV cases have been diagnosed in patients between the ages of 20 and 34 (1).

The aim of this study was to provide valid data related to HIV knowledge and sexual behaviour. This study was designed as the second in a series regarding HIV/AIDSrelated knowledge, attitudes and sexual practices among young people in Montenegro as a part of the national HIV response monitoring and evaluation framework. These than half reported current sexual activity. The reported level of sexual risk behaviour differed significantly according to participant sex and region. Early sexual initiation and not using condoms during the first episodes of sexual intercourse were found to be significant predictors of more frequent sexual risk behaviour.

Conclusions: Despite the relatively high awareness pertaining to routes of HIV transmission, the surveyed population reported misconceptions related to HIV transmission. A significant proportion of young people have engaged in risky sexual behaviours. These results strongly support the introduction of secondary school curriculum related to HIV/STI prevention as well other risk behaviours observed in this age cohort.

Keywords HIV - Young people-Sexual risk behaviour - Montenegro 


\section{METHODS}

\section{Participants}

This cross-sectional household survey was conducted in a nationally representative sample $(n=1,200)$ of young people aged 15-24 in December 2009. The overall participation rate was $97 \%$.

The sampling frame was based on the Census of Populations, Households and Dwellings completed in 2003. A sample size of 1,200 was calculated to provide a precision of $3 \%$, an expected prevalence of $50 \%$ for the indicator "Misconception related to HIV transmission", an expected refusal rate of $10 \%$ and a confidence interval of $95 \%$. The sample was created as a two-stage stratified probability sample, with the enumeration areas as primary sampling units and households as secondary units. The enumeration areas, as primary sampling units, were stratified according to the type of settlement (urban/rural) and region (northern, central or southern) and were selected in proportion to the number of persons aged 15-24 years. A list of households for the selected enumeration areas (households with at least one member aged 15 to 24 years) was used as a sampling frame for the selection of secondary units. From each previously selected enumeration area, 10 households were selected with equal probability (simple random sample). In households with more than one member aged 15-24, the person with the most recent birthday was sampled.

The questionnaire consisted of two parts. The first part was comporised of questions related to knowledge, attitudes and beliefs and was completed by an interviewer in a face-to-face setting. The second part contained questions related to sexual behaviour and was self-administered.

\section{Data collection instruments}

A knowledge, attitudes, practices and beliefs-structured (KAPB) questionnaire, containing 169 variables, was used. The first part of the questionnaire included sociodemographic data and questions related to the following items: personal and family background (education, activity, economic status and parental monitoring), HIV/AIDSrelated knowledge, attitudes towards people living with HIV/AIDS, attitudes towards gender sexual roles, peer norms, information sources, sensation seeking, locus of control and self-esteem.

The self-administered portion of the questionnaire included questions regarding types of sexual experiences, age at first intercourse, number of sexual partners during the previous 12 months, number of lifetime partners, condom use at first intercourse, condom use at last intercourse, condom use at last intercourse with non-regular partner, frequency of condom use during the previous 12 months (never, sometimes, always), attitudes towards condom use, self-efficacy in relation to condom use, self-reported symptoms of STIs, HIV testing, concurrent relationships and use of relevant reproductive health services.
The questionnaire was piloted with 20 participants, and those households were omitted from the final sampling frame. The final version of the questionnaire was adjusted in accordance with the pilot survey findings.

\section{Measures}

The HIV/AIDS knowledge scale contained 7 standardised items (Cronbach's $\alpha=0.6314$ ) related to knowledge regarding modes of HIV transmission prevention (such as "Is it possible to prevent HIV transmission by having sex exclusively with one healthy and faithful partner?") and including major misconceptions related to HIV transmission (such as the possibility of HIV transmission through mosquito bites, use of public toilettes, or sharing food with an HIV-infected person). All correct answers were coded as 1 , while false and "don't know" answers were coded as 0 .

The parental monitoring scale contained 4 questions - parental awareness of their children's whereabouts in the evening, how their children spent their money and spare time and who their children maintained as friends. The parental monitoring scale was scored as a composite of these four questions (Cronbach's $\alpha=0.7845$ ) with a theoretical range of 4-12 and a mean score of $\mathrm{M}=11.17$ ( $\mathrm{SD}=1.41,95 \%$ CI 11.08-11.25), with higher numbers indicating stronger parental control. More than $60 \%$ of the respondents had scores of 12 , meaning that they had perceptions of high levels of parental monitoring, while more than $90 \%$ had scores $\geq 10$.

Attitudes towards PLHIV were examined through 16 questions measuring acceptance of PLHIV and those populations most at -risk for HIV infection. The acceptance of PLHIV scale was calculated as a score of these 16 recorded items (Cronbach's $\alpha=0.8189$ ), where negative responses were coded as 0 and positive responses were coded as 1 . The possible range of scale values was 0 to 16 , with a higher score indicating a more open attitude towards PLHIV.

The "attitudes towards condom use” scale was calculated as a 5-point Likert scale measuring concordance with 10 statements about condom use, norms and effectiveness (Cronbach's $\alpha=0.669$ ). The values recorded ranged from 10 to 50 , with higher codes indicating more positive attitudes towards condom use, ii.e., stronger motivation. The mean score of this index was $35.12(\mathrm{SD}=5.65)$, with scores ranging from 15 to 50.

The self-efficacy index was calculated as a scale consisting of 9 items referring to the assessment of personal ability for condom use (purchasing, negotiation of its use and proper use, Cronbach's $\alpha=0.825)$. Values ranged from 9 to 45 and certain items were recorded such that higher scores indicated higher perceptions of self-efficacy The range of the index was 10-40 with a mean value of 26.92 $(\mathrm{SD}=6.6)$.

The Sexual Risk Taking Index was formed as a scale consisting of 6 behavioural dimensions that were linked with the risk of contracting HIV or another STI (condom use [never/sometimes], sex under the influence of alcohol, 
sex under the influence of drugs, more than 2 sexual partners in the previous 12 months, non-condom use at last sexual intercourse with non-regular partner, and concurrent relationships), with a 0-6 score range. For the purpose of logistic regression analysis, the SRT index was dichotomised such that 0 indicated respondents with no risk behaviours experienced and 1 indicated respondents with an index value of 1-5.

\section{Statistical Methods}

The frequency distributions for all examined variables were calculated and presented. Univariate associations of potential predictors with sexual risk behaviours were examined. To adjust for multiple predictors of risky sexual behaviours simultaneously, multivariate logistic regression was performed. Separate models were constructed for men and women. All variables that were significant in the univariate analysis as well as those shown to be significant in the literature were included in the logistic regression model. The backward stepwise procedure was used to determine the final model. The fitness of the final model was assessed using the Hosmer-Lemeshow test (6).

\section{RESULTS}

\section{Demographic characteristics}

The mean age of the participants was 19.28 years $(\mathrm{SD}=2.63)$. Almost half of the participants, 555, were from the central region (47.7\%), $346(29.7 \%)$ were from the northern part of Montenegro, and 263 (22.6\%) were from the southern coastal region. Of all participants, 848 (72.9\%) were from urban areas, and 316 (27.1\%) were from rural settlements. The basic socio-demographic characteristics of the sample are presented in Table 1.

\section{HIV/AIDS Knowledge}

The proportion of respondents who provided correct answers to individual HIV knowledge questions varied from 56.5\% („Could HIV be contracted if using a glass used by an HIV-infected person?") to $86 \%$ for showing awareness of condom use as the best prevention method concerning the sexual transmission of HIV. Misconceptions regarding HIV transmission were still present to a significant extent. More than one -third of respondents believed that HIV could be transmitted through sharing a meal with an HIV-infected person or using a public toilette. One -fifth (20.3\%) were not aware that HIV could be transmitted by having sexual intercourse with a healthy looking person.

The mean score of the HIV/AIDS knowledge scale was 4.88 (SD=1.75, 95\% CI 4.78-4.98). Slightly less than half of the respondents had scores of 6 or 7 , while almost one -fourth had scores $\leq 3$. Only $21.2 \%$ of the respondents gave correct answers to all 7 questions. There was no difference between genders $(t=-1.122, p=0.262)$.
There was no difference in the knowledge level shown between male and female participants $(t=-1.122, p=0.262)$. A regional comparison of the HIV/AIDS knowledge scale revealed significant differences $(\mathrm{F}=16.459, \mathrm{df}=2, \mathrm{p}<0.001)$. The best knowledge scores were derived from respondents of the coastal region, and the worst were from respondents of the northern region. Respondents from urban settlements scored significantly higher in comparison to their peers from rural settlements $(M=5.0$ compared to $\mathrm{M}=4.5, \mathrm{t}=4.51, \mathrm{p}<0.001)$. Respondents under the age of 18 scored lower than those over 18 (39.9\% of respondents aged 15-17 compared to $47.3 \%$ of respondents $18-24$ had high scores [ 6 or 7$\left.], \mathrm{X}^{2}=5.71 ; \mathrm{df}=1, \mathrm{p}<0.05\right)$. Exposure to HIV-related information at school (from a basic level up to participation in peer education programmes) was correlated with significantly higher HIV knowledge index scores $(\mathrm{F}=11.395, \mathrm{p}<0.001)$.

\section{Attitudes towards PLHIV}

The results revealed a significant stigma towards PLHIV as expressed by the fact that $45 \%$ of the surveyed young people would not share a meal, $35 \%$ would not share a desk and $32 \%$ would not hang out with an HIV-infected person, while $67 \%$ of young people would not buy food from an HIV-infected vendor. Thirty-three percent declared that an HIVinfected teacher should not be allowed to continue teaching, while $22 \%$ thought that HIV-infected pupils should not be allowed to continue attending regular school.

The mean score of this scale was 8.36 , with 8.13 (95\% CI 7.83-8.42) among males, and a slightly higher score of 8.63 among females (95\% CI 8.32-8.95, $\mathrm{t}=-2,310, \mathrm{p}=0,021$ ). Only $40 \%$ of the surveyed young people had scores above the median value (Med=9), while only one - sixth of the respondents scored $\geq 13$, which indicated a high level of acceptance towards PLHIV. The level of acceptance of PLHIV was positively correlated with education level $(\rho=0.124$, $\mathrm{p}<0.001)$ and scores on the HIV/AIDS knowledge scale $(\rho=0.443, p<0.001)$.

Univariate analysis revealed that scores of this scale varied asignificantly depending on the type of settlement (19.3\% of urban and $8.6 \%$ of rural youth surveyed expressed high levels of acceptance, $X^{2}=19.197 ; \mathrm{df}=2, \mathrm{p}<0.001$ ), the size of the place in which participants had lived the majority of their lives (higher acceptance in places with more than 10,000 inhabitants, $\left.X^{2}=24.99 ; \mathrm{df}=6, \mathrm{p}<0.001\right)$, age (younger respondents revealed lower levels of acceptance, $\left.X^{2}=23.83 ; \mathrm{df}=2, \mathrm{p}<0.001\right)$, and the education levels of both parents and the participants themselves (12.2\% of young people with primary education compared to $19 \%$ of young people with secondary and $26 \%$ with college/university education revealed high levels of acceptance toward people living with $\mathrm{HIV}, \mathrm{X}^{2}=21.08$; $\left.\mathrm{df}=4, \mathrm{p}<0,001\right)$. There were no differences between participants of various regions $(\mathrm{F}=1.59, \mathrm{p}>0,05)$. A higher frequency of discussions with participants' mothers 


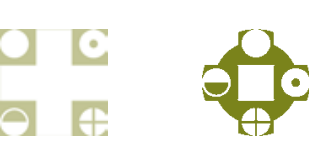

Table 1. Basic socio-demographic characteristics of the sample by gender

\begin{tabular}{|c|c|c|c|}
\hline Age & Males $(\mathrm{n}=620)$ & Females $(\mathrm{n}=544)$ & Total $(n=1164)$ \\
\hline 15 & $58(9.4)$ & $62(11.4)$ & $120(10.3)$ \\
\hline 16 & $67(10.8)$ & $61(11.2)$ & $128(11.0)$ \\
\hline 17 & $73(11.8)$ & $62(11.4)$ & $135(11.6)$ \\
\hline 18 & $64(10.3)$ & $61(11.2)$ & $125(10.7)$ \\
\hline 19 & $52(8.4)$ & $45(8.3)$ & $97(83)$ \\
\hline 20 & $76(12.3)$ & $59(10.8)$ & $135(11.6)$ \\
\hline 21 & $51(8.2)$ & $49(9.0)$ & $100(8.6)$ \\
\hline 22 & $74(11.9)$ & $52(9.6)$ & $126(10.8)$ \\
\hline 23 & $55(8.9)$ & $50(9.2)$ & $105(9.0)$ \\
\hline 24 & $50(8.1)$ & $43(7.9)$ & $93(8.0)$ \\
\hline \multicolumn{4}{|l|}{ Type of settlement * } \\
\hline Urban & $436(70.3)$ & $412(75.7)$ & $848(72.9)$ \\
\hline Rural & $184(29.7)$ & $132(24.3)$ & $316(27.1)$ \\
\hline Lived with both parents by the age of 18 & $559(90.7)$ & $491(90.9)$ & $1050(90.8)$ \\
\hline Currently live with parents & $583(94.3)$ & $505(93.5)$ & $1088(94.0)$ \\
\hline \multicolumn{4}{|l|}{ Mother's education } \\
\hline Up to primary school completed & $90(14.6)$ & $91(16.9)$ & $181(15.7)$ \\
\hline Secondary school Completed & $430(69.8)$ & $354(65.7)$ & $784(67.9)$ \\
\hline College/university & $96(15.6)$ & $94(17.4)$ & $190(16.5)$ \\
\hline \multicolumn{4}{|l|}{ Father's education } \\
\hline Up to primary school completed & $41(6.8)$ & $50(9.4)$ & $91(8.0)$ \\
\hline Secondary school Completed & $416(68.5)$ & $354(66.3)$ & $770(67.5)$ \\
\hline College/university & $150(24.7)$ & $130(24.3)$ & $280(24.5)$ \\
\hline \multicolumn{4}{|l|}{ Participant's occupation $*$} \\
\hline Secondary school student & $249(40.2)$ & $240(44.1)$ & $489(42.0)$ \\
\hline College/University student & $167(26.9)$ & $164(30.1)$ & $331(28.4)$ \\
\hline Employed & $100(16.1)$ & $64(11.8)$ & $164(14.1)$ \\
\hline Unemployed/housekeeper & $104(16.8)$ & $76(13.9)$ & $180(15.4)$ \\
\hline \multicolumn{4}{|l|}{ Family socio-economic status } \\
\hline Worse than average & $32(5.2)$ & $23(4.2)$ & $55(4.7)$ \\
\hline Average & $466(75.3)$ & $401(73.7)$ & $867(74.5)$ \\
\hline Better than average & $121(19.5)$ & $120(22.1)$ & $241(20.7)$ \\
\hline \multicolumn{4}{|l|}{ Marital status } \\
\hline Single & $602(97.1)$ & $511(94.5)$ & $1113(95.9)$ \\
\hline Married & $14(2.3)$ & $26(4.8)$ & $40(3.4)$ \\
\hline Cohabitating & $3(0.5)$ & $2(0.4)$ & $5(0.4)$ \\
\hline Divorced & $1(0.2)$ & $2(0.4)$ & $3(0.3)$ \\
\hline \multicolumn{4}{|c|}{ Size of the settlement where participants had lived the majority of their lives } \\
\hline Village & $126(20.4)$ & $87(16.1)$ & $213(18.3)$ \\
\hline Place with $<10,000$ inhabit. & $87(14.1)$ & $80(14.8)$ & $167(14.4)$ \\
\hline \multicolumn{4}{|l|}{ More than 10,000 and less } \\
\hline than 50,000 inhabitants & $172(27.4)$ & $175(32.5)$ & $347(29.9)$ \\
\hline$>50,000$ inhabitants & $234(37.8)$ & $200(36.9)$ & $434(37.4)$ \\
\hline \multicolumn{4}{|c|}{ Gender differences: ${ }^{*} \mathrm{p}<0.05,{ }^{* * *} \mathrm{p}<0.01,{ }^{* * * *} \mathrm{p}<0.001$} \\
\hline
\end{tabular}


Table 2. Sexual behaviour by gender

\begin{tabular}{|c|c|c|c|}
\hline & Males $(\mathrm{n}=620) \mathrm{N}(\%)$ & Females $(n=544) N(\%)$ & Total $(n=1164) N(\%)$ \\
\hline Have had vaginal intercourse ${ }^{* * *}$ & $397(64.0)$ & $197(36.2)$ & $594(51.7)$ \\
\hline Have had anal intercourse ${ }^{* * *}$ & $263(43.1)$ & $88(16.4)$ & $351(30.6)$ \\
\hline Have had oral intercourse ${ }^{* * *}$ & $131(21.5)$ & $33(6.1)$ & $164(14.3)$ \\
\hline \multicolumn{4}{|l|}{ Age at first sexual intercourse } \\
\hline 14 and younger & $44(10.6)$ & $1(0.5)$ & 45 (7.5) \\
\hline 15 & 49 (11.9) & $3(1.5)$ & $53(8.7)$ \\
\hline 16 & $111(27.0)$ & $14(7.2)$ & $125(20.6)$ \\
\hline 17 & $87(21.2)$ & $33(16.9)$ & $120(19.8)$ \\
\hline 18 & $70(17.0)$ & $57(29.2)$ & $127(21.0)$ \\
\hline 19 & $31(7.5)$ & $43(22.1)$ & $74(12.2)$ \\
\hline 20 and older & $19(4.6)$ & $43(22.1)$ & $61(10.1)$ \\
\hline \multicolumn{4}{|c|}{ Number of partners during previous 12 months*** } \\
\hline 0 & $25(6.3)$ & $13(6.7)$ & $38(6.4)$ \\
\hline 1 & $142(35.7)$ & $146(75.3)$ & $288(46.6)$ \\
\hline 2 & 95 (23.9) & 25 (12.9) & $120(20.3)$ \\
\hline 3 & 45 (11.3) & $8(4.1)$ & $53(9.0)$ \\
\hline $4+$ & $91(22.8)$ & $2(1.0)$ & $93(15.7)$ \\
\hline \multicolumn{4}{|l|}{ Number of lifetime partners $* * *$} \\
\hline 1 & $56(14.5)$ & $105(54.4)$ & $161(27.9)$ \\
\hline 2 & $50(13.0)$ & $33(17.1)$ & $83(14.4)$ \\
\hline 3 & $46(11.9)$ & $28(14.5)$ & $74(12.8)$ \\
\hline $4+$ & $233(60.6)$ & $27(14.0)$ & $260(44.9)$ \\
\hline Condom use at first intercourse & 262 (63.9) & $119(60.7)$ & 381 (62.9) \\
\hline Condom use at last intercourse* & $268(65.8)$ & $107(55.2)$ & $375(62.4)$ \\
\hline $\begin{array}{l}\text { Had a non-regular partner during the previous } \\
12 \text { months*** }\end{array}$ & $182(44.5)$ & $21(10.7)$ & $203(33.6)$ \\
\hline $\begin{array}{l}\text { Condom use at last intercourse with } \\
\text { non-regular partner }\end{array}$ & 207 (70.9) & $32(55.2)$ & 239 (67.9) \\
\hline $\begin{array}{l}\text { Sex under the influence of alcohol in the } \\
\text { previous } 12 \text { months }\end{array}$ & $156(38.1)$ & 39 (19.9) & $195(32.2)$ \\
\hline $\begin{array}{l}\text { Sex under the influence of drugs } \\
\text { in the previous } 12 \text { months }\end{array}$ & $11(2.7)$ & $1(0.5)$ & $12(2.0)$ \\
\hline Concurrent relationships (ever) & 204 (49.9) & $11(5.6)$ & $15(35.3)$ \\
\hline \multicolumn{4}{|l|}{ Condom use during the previous 12 months ** } \\
\hline Never & $46(11.7)$ & $38(21.0)$ & $84(14.6)$ \\
\hline Sometimes & $160(40.7)$ & $77(42.5)$ & $237(41.3)$ \\
\hline Always & $187(47.6)$ & $66(36.5)$ & $253(44.1)$ \\
\hline \multicolumn{4}{|c|}{ Condom use during oral sex during the previous 12 months ** } \\
\hline Never & $141(49.0)$ & $73(73.0)$ & $214(55.2)$ \\
\hline Sometimes & $68(23.6)$ & $13(13.0)$ & $81(20.9)$ \\
\hline Always & $79(27.4)$ & $14(14.0)$ & $93(24.0)$ \\
\hline
\end{tabular}


regarding sexual topics was shown to be a significant predictor of an accepting attitude $(20.8 \%$ of those who talked with their mothers about topics related to sex often/always had positive attitudes towards PLHIV compared to $14.8 \%$ of those who talked with their mothers rarely or never, $\left.\mathrm{X}^{2}=17.958 ; \mathrm{df}=2, \mathrm{p}<0.001\right)$. A positive association between exposure to HIV-related information and a higher level of acceptance of PLHIV was revealed $(\rho=0.143, p=0.000)$.

\section{Sexual behaviour}

Approximately one -half of the participants declared having had certain sexual experiences. The major characteristics of the sexual behaviour of the surveyed population are summarised in Table 2. Respondents from the coastal region reported sexual activity to a greater extent than their peers from the central and northern regions.

On average, the young people surveyed first experienced sexual intercourse at the age of $17.2(\mathrm{SD}=1.8)$, with males $(16.6, \mathrm{SD}=1.7)$ reporting significantly earlier sexual experiences $(\mathrm{t}=-12.91, \mathrm{p}<0.001)$ than females $(18.4, \mathrm{SD}=1.6)$. The majority of sexually active respondents $(61.4 \%)$ first had sexual intercourse between the ages of 16 and 18 (65.2\% males and $53.3 \%$ females), with $22.4 \%$ older than 18 and $16.2 \%$ (22.6\% males and $2.6 \%$ fe-

Figure 2. Number of partners in the previous 12 months with regard to the level of parental monitoring

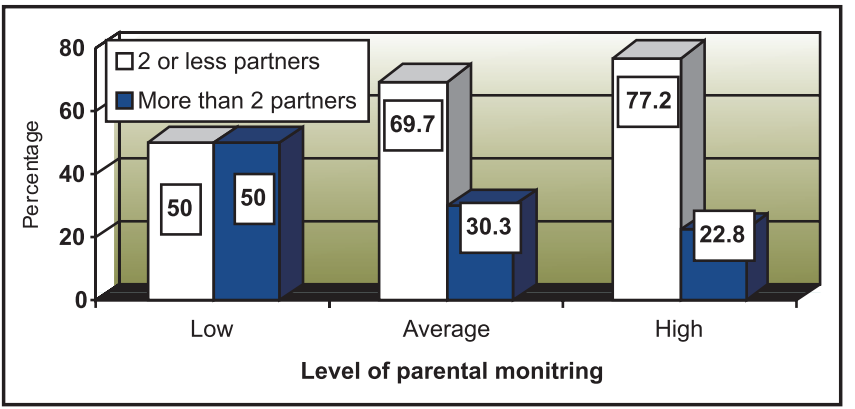

Figure 1. Sexual risk -taking by gender

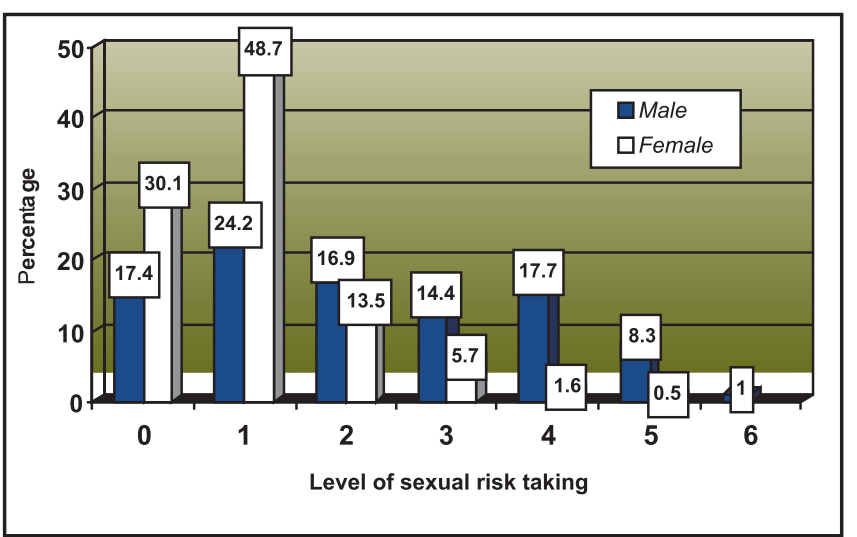

males) younger than 16 at their first sexual intercourse. Only $8.2 \%$ declared that they had entered into sexual activities too early, with no difference between genders.

Sixty-three percent of young people used condoms during their first intercourse. A positive association between condom use at first intercourse and exposure to HIV-related information at school was observed $(\rho=0.18, p=0.000)$.

From those who reported having had sexual intercourse, $93.3 \%$ were sexually active during the previous 12 months. Of all participants, $48.6 \%$ had only one partner during the previous 12 months, while $15.7 \%$ had 4 or more partners, with males having had significantly more partners than females $\left(\operatorname{Med}_{\mathrm{m}}=2, \mathrm{M}_{\mathrm{m}}=2.63, \mathrm{SD}_{\mathrm{m}}=2.76 ; \operatorname{Med}_{\mathrm{f}}=1\right.$, $\left.\mathrm{M}_{\mathrm{f}}=1.31, \mathrm{SD}_{\mathrm{f}}=2.16, \mathrm{t}=9.197, \mathrm{p}<0.001\right)$.

A higher extent of parental monitoring was correlated with reduced numbers of partners (Figure 2).

More than one -third of the respondents who were sexually active before the age of 16 had 4 or more partners during the previous 12 months $\left(\chi^{2}=60.72 ; d f=5\right.$, $\mathrm{p}<0.001)$. Young people with higher scores on the sensation-seeking scale were prone to higher numbers of sexual partners $\left(\chi^{2}=9,969 ; \mathrm{df}=1, \mathrm{p}<0,01\right)$. Considering the number of lifetime partners, $54.4 \%$ of females had just one partner, while more than three -fifths of males had 4 or more partners.

One -fourth of men and $3.1 \%$ of women reported that their last sexual intercourse was casual $\left(\chi^{2}=43.25\right.$; $\mathrm{df}=1, \mathrm{p}<0,001)$.

Early sexual initiation was a significant predictor of more frequent sex with non-regular partners $(57.8 \%$ of those who had sexual intercourse $\leq 16$ years of age had experienced sex with a non-regular partner compared to $19.2 \%$ of those respondents who first had sexual intercourse at age 17 or older, $\left.\chi^{2}=94.17 ; \mathrm{df}=1, \mathrm{p}<0,001\right)$. A positive correlation was revealed between higher scores on the sensation-seeking scale and sex with non-regular partners $(\rho=0,269, p<0,001)$.

Inconsistent condom use was associated with the perception that condoms destroy the spontaneity of the sexual act $\left(\rho=-0,259^{* * * *)}\right.$ or create erectile dysfunction $(\rho=-$ $\left.0,212^{* * *}\right)$ and beliefs that the person suggesting condom use does not have confidence in the partner $\left(\rho=-0,102^{*}\right)$. A higher level of positive attitudes towards condom use $\left(\rho=0,298^{* * * *}\right)$ and a higher perception of self-efficacy related to the negotiation and proper use of condoms $\left(\rho=0,197^{* * * *}\right)$ were shown to be positively associated with more frequent condom use.

\section{Sexual Risk Behaviours}

The survey results revealed that more than three -fourths of respondents, to different extents, have engaged in sexual risk behaviour. Males engaged in sexual risk behaviour to a much greater extent than females $\left(x^{2}=86.03\right.$; $\mathrm{df}=6, \mathrm{p}<0,001)$. The mean score of this index was $1.81(2.20$ for males, 1.02 for females), with $41.4 \%$ of males and just $7.8 \%$ of females having scores $\geq 3$. 


\begin{tabular}{|c|c|c|c|}
\hline & Total $(\mathrm{N}=486)$ & Women $(\mathrm{N}=337)$ & Men $(\mathrm{N}=149)$ \\
\hline \multicolumn{4}{|l|}{ Respondent's education level } \\
\hline Completed primary school or less ${ }^{\circledR}$ & & & 1 \\
\hline Secondary school & & & 0.0006 \\
\hline College/university & & & 0.0017 \\
\hline \multicolumn{4}{|l|}{ Father's education level } \\
\hline Completed primary school or less ${ }^{\circledR}$ & 1 & 1 & \\
\hline Secondary school & $0.51(0.15-1.73)$ & $0.79(0.09-6.59)$ & \\
\hline College/university & $0.37(0.18-0.78)$ & $0.17(0.05-0.62)$ & \\
\hline \multicolumn{4}{|l|}{ Mother's education level } \\
\hline Completed primary school or less ${ }^{\circledR}$ & 1 & 1 & \\
\hline Secondary school & $0.46(0.17-1.23)$ & $0.32(0.06-1.57)$ & \\
\hline College/university & $1.23(0.57-2.64)$ & $1.53(0.47-4.95)$ & \\
\hline "Most of my friends think it's normal to have sex on the first date." & $1.79(1.04-3.08)$ & & $2.76(1.45-5.27)$ \\
\hline "Most of my friends have negative attitudes towards condom use." & $2.24(1.08-4.66)$ & & \\
\hline Condom use at first sexual intercourse & $0.16(0.08-0.30)$ & $0.08(0.03-0.25)$ & $0.22(0.09-0.51)$ \\
\hline Sexual initiation at the age $\leq 15$ & $2.34(1.23-4.45)$ & & $2.39(1.20-4.81)$ \\
\hline $\begin{array}{l}\text { Talking about sexual life with the partner } \\
\text { (often/always) }\end{array}$ & $1.66(0.93-2.95)$ & $2.95(1.01-8.56)$ & \\
\hline $\begin{array}{l}\text { Talking about sexual life with best friend } \\
\text { (often/always) }\end{array}$ & $1.85(1.01-3.41)$ & & \\
\hline Attitudes towards condom use & $0.95(0.91-0.98)$ & & $0.93(0.87-0.98)$ \\
\hline High level of parental monitoring & $0.57(0.32-1.02)$ & & $0.41(0.20-0.87)$ \\
\hline \multicolumn{4}{|l|}{ Gender } \\
\hline Male ${ }^{\circledR}$ & 1 & & \\
\hline Female & $0.52(0.30-0.42)$ & & \\
\hline Age & $1.23(1.09-1.38)$ & & \\
\hline
\end{tabular}

Table 3. Logistic regression models regarding sexual risk -taking by gender (odds ratios and 95\% confidence intervals)

The overall logistic regression model was constructed including 486 participants. Separate models were constructed for male and female participants to understand the gender-induced differences in the predictors of sexual risk behaviours. All three models are presented in Table 3.

Females were less prone to sexual risk behaviour $(\mathrm{OR}=0.52)$ than their male peers. The logistic regression model for all respondents revealed that higher education levels of the father or mother as well as higher levels of parental monitoring were significant prevention factors for sexual risk behaviours $(\mathrm{OR}=0.57)$. Condom use at first intercourse was shown to have the strongest protective effect concerning all respondents $(\mathrm{OR}=$ $0.16)$ as well as males $(\mathrm{OR}=0.08)$ and females $(\mathrm{OR}=0.22)$ alone. More positive attitudes towards condom use were significant in the model for all respondents as well as thatfor male respondents, while more frequent discussions about sexual life with the partner was shown to be a risk factor in the model for all respondents $(\mathrm{OR}=1.66)$ and for women $(\mathrm{OR}=2.95)$. Early sexual initiation was a significant risk factor in the overall model $(\mathrm{OR}=2.34)$ as well as in that for the male participants $(\mathrm{OR}=2.39)$.

\section{DISCUSSION}

The present study evaluated the level of HIV-related knowledge and accepting attitudes towards PLHIV as well as the level of risk behaviours related to the transmission of HIV and other STIs.

Overall, the level of knowledge was satisfactory in terms of the prevention of sexual transmission of HIV. However, misconceptions related to HIV transmission were still present in more than one -third of the surveyed population. The knowledge level in this study was slightly higher than that in a previous study from 2007, which surveyed a population aged 18-24 (2). A regional comparison revealed significant differences in the knowledge levels between participants from the north region and other parts of Montenegro (central and coastal regions). Peer education programmes as well as other prevention programmes were significantly correlated with increased levels of knowledge. The knowledge level of those surveyed was similar to that of young people in Croatia, but unlike in the Croatian participants, no gender differences were observed in this study $(7,8)$. 
The level of acceptance of PLHIV was unsatisfactory, as only one -sixth of the surveyed population scored more than 13 on a $0-16$ scale, with slightly more positive attitudes among the female respondents. Older respondents, respondents from urban settlements and respondents with higher levels of HIV-related knowledge were more open towards possible contact with HIV-infected people. Having received HIV-related information at school was also associated with higher levels of acceptance of PLHIV.

Slightly more than half of the surveyed population were reported being sexually active, with significantly more prevalent sexual activity among males. The results showed significant gender differences in sexual behaviour, with women taking fewer risks than men, which is consistent with the findings in a large number of questionnaire and experimental studies $(9,10)$.

The level of sexual risk behaviours reported varied from $2 \%$ for sex under the influence of drugs to $56 \%$ for inconsistent condom use. Sixteen percent of participants engaged in sexual activity under the age of 16 , which is consistent with the results reported in studies conducted in other central and south-eastern European countries (11). Additionally, $72 \%$ of males and $28.5 \%$ of females had 3 or more partners thus far, with $33 \%$ of males and $5 \%$ of females reporting multiple partners within the previous 12 months. Respondents reporting early sexual initiation were significantly more likely to engage in other sexual risk behaviours such as multiple partners, inconsistent condom use and sex under the influence of alcohol (12).

Consistent condom use is considered one of the most effective prevention strategies for reducing the risk of transmission of HIV and other STIs $(13,14)$. Individuals who used condoms during their first intercourse were significantly more likely to subsequently use condoms regardless of the partner. Contraception used during first intercourse was associated with subsequent consistent contraception use (15). Of those who consistently used condoms during the previous 12 months, $92 \%$ had used condoms during first intercourse, while $65 \%$ of those using condoms at first intercourse remained faithful to that habit. During participants' last sexual intercourse, condoms were used by $66 \%$ of respondents, with significantly higher percentages among males than females, while almost the same proportion (68\%) used condoms during the last intercourse with non-regular partners, showing no difference in this study population compared to young people surveyed in Montenegro in 2007 (2). Despite the relatively high level of knowledge with regard to the sexual transmission of HIV, consistent condom use remains a habit in less than half of the surveyed population.

Older respondents were more prone to risk-taking behaviours than their younger peers. Self-esteem and self-efficacy were not found to be predictive of sexual risk behaviours, which is consistent with a survey of Slovak students but not with the findings of several other studies $(16,17,18)$, where they were found to be predictive for protective as well as for risk-taking behaviours such as multiple partners (11).
Condom use at first intercourse proved to be the strongest protective factor in both genders for not engaging in sexual risk behaviours, which is consistent with the findings in several studies related to condom use predictors $(19,20,21)$. Respondents who used condoms during first intercourse were significantly more frequent condom users at last intercourse, regardless of partner, and were consistent condom users in general. Positive attitudes towards condom use and stronger self-efficacy were predictors of condom use, which is consistent with other studies that investigated predictors of condom use among adolescent and young adult populations (22).

A higher level of parental monitoring was a significant protective factor in the overall logistic regression model for the level of sexual risk -taking and in the model for male respondents, which is consistent with the findings in other surveys showing that supervision is related to boys' risk behaviours $(23,24,25)$.

Among the limitations of cross-sectional studies is that the causality of the associations revealed cannot be established. Further limitations result from the possible participation and recall bias due to the retrospective nature of the study (frequency of condom use, number of partners (26), age at first sexual intercourse $(27,28))$ and the provision of socially desirable answers (29). The methodological advantages of this study result from the reliable sampling framework and pre-tested data collection methods. The validity of the self-reported data was further increased by using anonymous questionnaires, which were partially self-administered, and pre-testing the questionnaire for understanding and precise recall of certain required data. To increase the response rate, special attention was paid to selection and training of the interviewers considering the sensitive nature of the behaviours to be studied. A response rate of $97 \%$ is relatively high and contributes to the validity of the data (30).

\section{IMPLICATIONS}

In light of raising awareness related to HIV/AIDS through the GFATM,- the subject "Healthy Life Styles" was included in the primary school curriculum as optional subject for $8^{\text {th }}$ or $9^{\text {th }}$ graders. It was designed to cover not only sexual and reproductive health in relation to HIV, but also healthy nutrition, mental health, communication, prevention of injuries, physical activity, substance abuse, and communal hygiene,.

Our results indicate that condom use at first intercourse was a strong predictor, for both boys and for girls, for subsequent more frequent condom use. Other studies have shown that school-based HIV prevention programmes have significant effects on students' self-efficacy for condom use and intentions to adopt prevention practices (31). This is a strong argument for condom promotion at early adolescence prior to entering into sexual activities, at higher grades of primary school and lower grades of secondary school. 
However, further research in the adolescent population is needed to obtain a more precise picture of the sexual behaviour of this age group and clarify which other factors contribute to different types of risk behaviours.

\section{Conclusions}

These findings confirm the hypothesis of significant gender and regional differences in the level of knowledge and accepting attitudes towards PLHIV and in the prevalence of risk sexual behaviour. Provision of HIV-related educational activities at school was positively associated with a higher level of HIV-related knowledge and acceptance of PLHIV (31) as well as a higher rate of condom use at first intercourse and consistent condom use thereafter. These results strongly support the idea of in-school HIVrelated educational activities as well as the introduction of secondary school curriculum related to HIV/STI prevention and other aspects of risk behaviour characterising this age population.

\section{Acknowledgements}

This survey was implemented by Institute of Public Health of Montenegro and financially supported by the Global Fund to Fight AIDS, Tuberculosis and Malaria through implementation of the Round 5 Grant "Support to implementation of HIV/AIDS strategy in Montenegro" managed by United Nations Development Programme - Country Office in Montenegro.

\section{REFERENCES}

1. Institute of Public Health. Annual Report on HIV in Montenegro in 2009. Podgorica, 2010.

2. Labovic I, Radulovic J, Strahinja R, Terzic N, Mugosa B, Lausevic D. HIV/AIDS related knowledge, attitudes and sexual behaviour in young adults, aged 18-24 years, in Montenegro, 2007. Institute of Public Health, Podgorica 2008.

3. Benotch EG, Pinkerton SD, Dyatlov RD, DiFranceisco W, Smirnova TS, Dudko VY, Kozlov A. HIV risk in male and female Russian sexually transmitted diseases clinic patients. International Journal of Behavioral Medicine 2006;13(1):26-33.

4. Dehne KL et al. The HIV/AIDS epidemic in Eastern Europe: recent patterns and trends and their implications for policy-making, AIDS 1999; 13(7):741-749.

5. Beadnell B, Morrison DM, Wilsdon A, Wells EA, Murowchick E, Hoppe M, Gillmore MR, Nahom D. Condom use, frequency of sex, and number of partners:multidimensional characterization of adolescent sexual risk-taking. J ournal of Sex Research 2005; 42(3):192-202.

6. Bewick V, Cheek L, Ball J. Statistic review 14:Logistic regression. Critical Care 2005; 9(1):112-118.
7. Stulhofer A, Graham C, Bozicevic I, Kufrin K, Ajdukovic D. HIV/AIDS-related knowledge, attitudes and sexual behaviors as predictors of condom use among young adults in Croatia. International Family Planning Perspectives 2007; 33(2):58-65.

8. Bozicevic I, Stulhofer A, Ajdukovic D, Kufrin K. Patterns of sexual behavior and reported symptoms of STI/RTIs among young people in Croatia - implications for interventions' planning. Coll Antrop 2006; 30 (Suppl 2):63-70.

9. Harris CR, Jenkins M, Glaser D. Gender differences in risk assessment:Why do women take fewere risks than men? Judgement and Decision Making 2006;1(1):48-63.

10. Byrnes JP, Miller DC, Schafer WD. Gender differences in risk taking:a meta-analysis. Psychological Bulletin 1999; 125:367-383.

11. Kalina O, Geckova AM, Jarcuska P, Orosova O, Van Dijk JP, Reijneveld SA: Psychological and behavioural factors associated with sexual risk behaviour among Slovak students. BMC Public Health 2009, 9:15.

12.Santelli JS, Brener ND, Lowry R, Bhatt A, Zabin LS. Multiple sexual partners among U.S. adolescents and young adults. Family Planning Perspectives 1998;30(6):271-275.

13. Gallo MF, Steiner MJ, Warner L, Hylton-Kong T, Figureoa JP, Hobbs MM, Behets FM: Self-reported condom use is associated with reduced risk of Chlamydia, gonorrhea, and trichomoniasis. Sex Transm Dis 2007; 34(10):829-33.

14. Santelli JS, Warren CW, Lowry R, Sogolow E, Collins J, Kann L, Kaufmann RB. Celentano DD. The use of condoms with other contraceptive methods among young men and women. Family Planning Perspectives 1997;29:261-267.

15. Manlove J, Ryan S, Franzetta K. Patterns of contraceptive use within teenagers' first sexual relationships. Perspectives on Sexual and Reproductive Health 2003;35(6):246-255.

16. McNair LD: Self-esteem, gender, and alcohol use: relationships with HIV risk perception and behaviors in college students. J Sex Marital Ther 1998, 24:29-36.

17. Cole FL, Slocumb EM. Factors influencing safer sexual behaviors in heterosexual late adolescents and young collegiate males. Image J Nurs Sch 1995;27(3):217-23.

18. Cole FL. The role of self-esteem in safer sexual practices. J Assoc Nurses AIDS Care 1997;8(6):64-70.

19. Hirsl-Hecej V, Stulhofer A. Urban adolescents and sexual risk taking. Collegium Anthropologicum 2006;30(Suppl 2):105-114.

20. Sheeran P, Abraham C, Orbell S. Psychosocial correlates of heterosexual condom use:a meta-analysis, Psychological Bulletin 1999;125(1):90-132.

21. Shafii T, Stovel K, Holmes H. Association between condom use at sexual debut and subsequent sexual trajectories: a longitudinal study using biomarkers. American Journal of Public Health 2007; 97(6):1090-1095. 
22. Brown LK, DiClemente R, Crosby R, Fernandez MI, Pugatch D, Cohn S, Lescano C, Royal S, Murphy JR, Silver B, Schlenger WE. Condom use among high-risk adolescents:anticipation of partner disapproval and less pleasure associated with not using condoms. Public Health Rep 2008;123(5):601-7.

23. Rodgers KB. Parenting processes related to sexual risktaking behaviors of adolescent males and females. Journal of Marriage and the Family 1999, 61:99-109.

24. Miller BC. Family influences on adolescent sexual and contraceptive behavior. Journal of Sex Research 2002, 39(1):22-26.

25. Cohen DA, Farley TA, Taylor SN, Martin DH, Schuster MA. When and where do youth have sex? The potential role of adult supervision. Pediatrics 2002;110(6).

26. Jeanin A, Konings E, Dubois-Arber F, Landert C, Van Melle G. Validity and reliability in reporting sexual partners and condom use in a Swiss population survey. European Journal of Epidemiology 1998;14(2):139-146.
27. Touraneau R et al. The Psychology of Survey Response, New York: Cambridge University Press, 2000.

28. Weinhardt LS, Forsyth AD, Carey MP, Jaworski, BA, Durant LE. Reliability and Validity of Self-Report Measures of HIV-Related Sexual Behavior Progress since 1990 and Recommendations for Research and Practice. Arch Sex Behav 1998; 27(2):155-180.

29. Catania JA, Gibson DR, Chitwood DD, Coates TJ. Methodological problems in AIDS behavioral research: Influences on measurement error and participation bias in studies of sexual behavior. Psychol. Bull. 1990; 108:339-362.

30. Fenton K, Johnson AM; McManus S, Erens B. Measuring sexual behavior: methodological challenges in survey research. Sex Transm Infect 2001; 77:84-92

31. Weeks K, Levy SR, Zhu C, Perhats C, Handler A, Flay BR. Impact of a school-based AIDS prevention program on young adolescents' self-efficacy skills. Health Education Research 1995; 10(3):329-344.

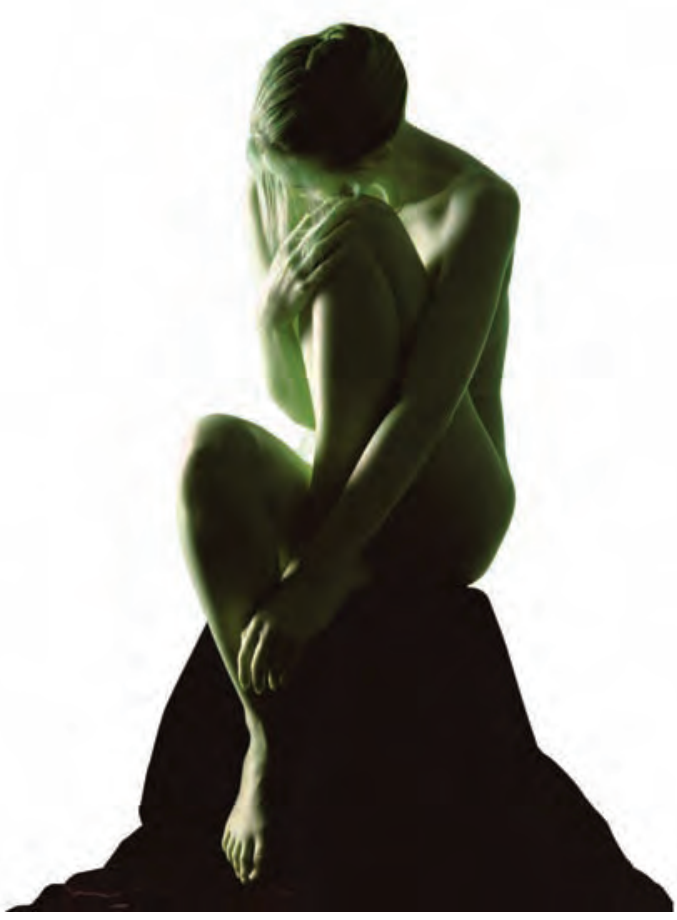

